\title{
Adaptação sócio-comunicativa no espectro autístico: dados obtidos \\ com pais e terapeutas
}

\section{Social communicative adaptation in the autistic spectrum: data provided by parents and therapists}

\author{
Priscilla Faria Sousa-Morato ${ }^{1}$, Fernanda Dreux Miranda Fernandes²
}

\begin{abstract}
RESUMO
Objetivo: Verificar a efetividade da aplicação do protocolo de adaptação sócio-comunicativa a diferentes fontes de informação, neste caso, pais e terapeutas, na identificação de diferenças individuais em crianças com Distúrbios do Espectro Autístico. Métodos: Participaram deste estudo 48 crianças, entre três anos e 11 anos e dez meses de idade, com diagnóstico clínico incluído no espectro autístico. Foram também sujeitos deste trabalho, 46 mães e dois pais, bem como 15 terapeutas, responsáveis legais e pelo atendimento fonoaudiológico especializado, respectivamente, das mesmas crianças, por um período mínimo de aproximadamente 12 meses, sendo que estes participaram respondendo a um questionário sobre o relacionamento social das crianças, sujeitos deste estudo. Resultados: Genericamente, pode-se dizer que as respostas sobre a adaptação sócio-comunicativa, obtidas por meio de diferentes fontes de informação, ou seja, pais e terapeutas foram semelhantes. Entretanto, analisando os dados brutos observa-se que os pais apresentaram consistentemente um número maior de respostas positivas do que as terapeutas, para as questões relativas ao desempenho social. Conclusão: $\mathrm{O}$ estabelecimento de dados de adaptação sócio-comunicativa pode caracterizar esta população, demonstrando que este instrumento pode ser aplicado a diferentes informantes; as respostas dadas pelos mesmos foram homogêneas, reforçando a fidedignidade dos dados, apesar de existirem diferenças significativas na comparação entre os níveis e estágios sócio-comunicativos. A aplicação do questionário e protocolo de adaptação sócio-comunicativa a diferentes informantes pode fornecer um resultado bastante homogêneo, sendo possível realizar de forma fidedigna a caracterização das habilidades de relacionamento social dessas crianças.
\end{abstract}

Descritores: Transtorno autístico; Socialização; Comunicação; Terapia da linguagem; Pais

\section{INTRODUÇÃO}

O estudo do autismo infantil vem se desenvolvendo ao longo de décadas, sendo que em um primeiro momento focouse mais a parte semiológica do distúrbio. Existem inúmeras pesquisas que demonstram a importância da linguagem e da comunicação, bem como a sua inter-relação com a cognição e a socialização na caracterização deste distúrbio do desenvolvimento ${ }^{(1-4)}$.

A linguagem apresenta-se enquanto fenômeno social sensível a dimensões como formalidade da situação, objetivos de interação e relação entre os interlocutores. Ou seja, é sensível

Trabalho realizado no Laboratório de Investigação Fonoaudiológica dos Distúrbios do Espectro Autístico do Curso de Fonoaudiologia da Faculdade de Medicina da Universidade de São Paulo - USP - São Paulo (SP), Brasil.

(1) Doutora, Professora do Curso de Fonoaudiologia da Universidade FUMEC - Belo Horizonte - (MG), Brasil.

(2) Livre-docente, Professora do Curso de Fonoaudiologia da Faculdade de Medicina da Universidade de São Paulo - USP - São Paulo (SP), Brasil.

Endereço para correspondência: Priscilla Faria Sousa-Morato. R. Santa Catarina, $1630,3^{\circ}$ andar, Lourdes, Belo Horizonte - MG, CEP: 30170-081.

E-mail: priscillafsmorato@yahoo.com.br

Recebido em: 6/8/2008; Aceito em: 26/12/2008 ao contexto, considerando este como o caminho que possibilita a distinção entre os efeitos da estrutura linguística e os efeitos da situação e que é, em parte, determinado pela cultura, o que gera diferenças nos detalhes do contexto interativo ${ }^{(5-6)}$.

As inabilidades de cunho social, de certa forma, são as mais marcantes em crianças autistas. Observam-se falhas em demonstrar interesse social ou afeição, especialmente, em relação a familiares próximos. Comportamentos sociais e de interação não estão ausentes no autismo, mas eles podem ser extremamente desviantes. Um dos fatores importantes na interpretação do comportamento social é o papel da familiaridade, rotinas e estruturação da participação desta criança em atividades sociais. Rotinas e atividades estruturadas reduzem a complexidade e a imprevisibilidade do mundo social, o que pode ser de extrema importância para crianças que não compreendem as razões mentais para as ações das pessoas ${ }^{(7-8)}$.

Teorias sobre o desenvolvimento do autismo sugerem que a intervenção precoce pode atenuar as sequelas negativas que resultam de déficits iniciais e que acabam interferindo tardiamente no funcionamento, considerando-a como um aspecto crítico no gerenciamento e no tratamento de crianças com autismo ${ }^{(9)}$. 
$\mathrm{Na}$ literatura nacional, quase não existem trabalhos que tratem desta relação tão estreita entre a linguagem e a socialização em crianças do espectro autístico. Se considerarmos que a linguagem e a socialização são mutuamente interferentes e que caminham juntas, permitindo ao indivíduo participar de relações sociais que expressam trocas comunicativas equilibradas, é de extrema importância que compreendamos a relação entre essas áreas do desenvolvimento nos distúrbios do espectro autístico ${ }^{(10)}$.

Em um estudo foram relacionados os aspectos de linguagem, desempenho sócio-cognitivo e relacionamento social de crianças do espectro autístico, sendo proposta uma forma de análise do relacionamento social de crianças do espectro autístico. Foi concluído que o material elaborado pela pesquisadora foi capaz de estabelecer o desempenho sócio-comunicativo, segundo a análise dos pais em relação à adaptação social de seus filhos. Entretanto, foi percebida a necessidade de uma análise e uma comparação dos mesmos aspectos, obtidos a partir da perspectiva de indivíduos que enxergam esse mesmo alvo, mas com outro foco, como as terapeutas ${ }^{(11)}$.

A consideração da perspectiva dos pais de crianças do espectro autístico quanto ao comportamento linguístico, cognitivo e social de seus filhos vem sendo colocada em um lugar de destaque, uma vez que estes passam a ser parceiros dos profissionais envolvidos no processo de intervenção, ajudando no monitoramento do nível de desenvolvimento destas crianças $^{(12-15)}$.

Investigando o uso da informação do contexto familiar para direcionar a avaliação e o processo terapêutico, observouse que o uso dessas informações em processos de avaliação e terapia não geram problemas, podendo contribuir para a estabilidade e durabilidade da redução de comportamentos desafiantes alcançados por meio de uma abordagem funcional da comunicação ${ }^{(16-18)}$.

Foi proposta a análise dos dados de adaptação sóciocomunicativa de crianças do espectro autístico, considerando também as terapeutas como informantes do questionário e protocolo, referentes ao relacionamento social dessas crianças.

Sendo assim, o objetivo deste trabalho foi verificar a efetividade da aplicação do protocolo de adaptação sóciocomunicativa a diferentes fontes de informação, neste caso; pais e terapeutas, na identificação de diferenças individuais em crianças com Distúrbios do Espectro Autístico (DEA).

\section{MÉTODOS}

Esta pesquisa foi encaminhada à Comissão de Ética da Faculdade de Medicina da Universidade de São Paulo e recebeu aprovação sob o protocolo número 420/04. Foi solicitada a autorização para a utilização dos dados, para fins de pesquisa, ao adulto responsável e às terapeutas responsáveis pelo cuidado de um cada dos sujeitos.

\section{Sujeitos}

Participaram deste estudo 48 crianças, entre três anos e 11 anos e dez meses de idade, com diagnóstico clínico incluído no espectro autístico, atribuído por médicos neurologistas e/ou psiquiatras, segundo critérios específicos ${ }^{(19-20)}$. Para a inclusão das referidas crianças, não foram adotados critérios como: nível intelectual, de escolaridade e tempo de exposição a outras abordagens terapêuticas.

Foram também sujeitos deste trabalho, 46 mães e dois pais, responsáveis pelas 48 crianças anteriormente citadas. Bem como, 15 terapeutas, responsáveis pelo atendimento fonoaudiológico especializado das mesmas crianças, por um período mínimo de aproximadamente 12 meses. Eles foram convidados a participar deste estudo respondendo a um questionário sobre o relacionamento social das crianças, sujeitos deste estudo.

Faz-se necessário lembrar que não houve critério de inclusão dos pais nesta pesquisa e que o nível sócio-econômico, intelectual e educacional dos mesmos não foi uma variável considerada.

\section{Procedimentos}

Para a coleta dos dados da adaptação sócio-comunicativa, foram utilizados o questionário e o protocolo específico, referentes à Escala de Adaptação Sócio-Comunicativa (EASC) $^{(10-11)}$. A EASC ${ }^{(10-11)}$ é composta por quatro níveis, cada um contendo quatro estágios referentes às habilidades sociais da criança. Os dados da EASC são obtidos pela aplicação de um questionário que admite respostas do tipo "sim" ou "não", sendo a classificação em nível sócio-comunicativo estabelecida quando a criança situa-se no maior nível em que apresente ao menos três respostas "sim". Este instrumento visa verificar variações individuais das habilidades sociais de crianças pelas respostas dos pais e/ou terapeutas sobre a forma como estes consideram seus filhos e/ou pacientes como agentes de ação e participação no meio comunicativo e social.

Sendo assim, os protocolos da adaptação sócio-comunicativa foram aplicados individualmente com os pais e terapeutas dos sujeitos, em entrevistas realizadas pela pesquisadora, sendo que os entrevistados deveriam responder sim ou não a questões relacionadas ao desempenho sócio-comunicativo de seus filhos e pacientes, respectivamente. A cada resposta sim, era marcado o número um (1) e a cada resposta negativa marcado o número zero (0) para possibilitar o estudo estatístico dos dados.

O mesmo procedimento foi realizado com pais e terapeutas após um mês do início do processo terapêutico fonoaudiológico no ano de 2005, entre os meses de abril e maio.

Para a aplicação deste questionário, perguntava-se ao entrevistado a respeito da primeira exemplificação fornecida; caso este não compreendesse ou não conseguisse responder, apresentava-se o segundo exemplo, sendo as respostas obtidas anotadas no protocolo de registro específico.

Para maior compreensão das idéias e classificações propostas pela escala de adaptação sócio-comunicativa, o questionário dirigido aos pais e às terapeutas e o protocolo de registro estão apresentados nos Anexos 1 e 2, respectivamente.

\section{Análise estatística}

O programa SPSS (Statistical Package for Social Sciences), em sua versão 14.0 foi utilizado como instrumento 
para análise estatística dos dados. Para a aplicação dos testes estatísticos deste estudo foi adotado o nível de significância de $5 \%(\alpha=0,050)$.

Para este estudo foi utilizado o teste de Wilcoxon, para identificar possíveis diferenças entre as informações obtidas pelo questionário de adaptação sócio-comunicativa colhidas com dois diferentes informantes. Foi realizada, ainda, uma análise estatística descritiva, CrossTabs, pela aplicação do Teste de McNemar ${ }^{(21)}$.

\section{RESULTADOS}

Na comparação entre o número de respostas positivas obtidas com pais e terapeutas dos sujeitos em cada estágio, de cada nível da escala de adaptação sócio-comunicativa, pode-se observar, na Figura 1, que o desempenho geral dos sujeitos em ambas as situações aparenta estar genericamente semelhante, apresentando somente três diferenças significativas, estando estas destacadas em amarelo.

De forma geral, pode-se dizer que as respostas quanto à adaptação sócio-comunicativa, obtidas por meio de diferentes fontes de informação, ou seja, pais e terapeutas, foram genericamente semelhantes. Entretanto, analisando os dados brutos observa-se que os pais apresentaram consistentemente um número maior de respostas positivas do que as terapeutas, para as questões relativas ao desempenho social de seus filhos.

Nas duas situações de coleta de dados pode-se notar uma diminuição mais acentuada no número de respostas positivas por parte dos dois informantes, pais e terapeutas dos sujeitos, como nos mostram as setas pretas na Figura 1. Esse resultado ocorre a partir do estágio dois do nível 2, que significa que a criança é capaz de se adaptar a mudanças e variações e a queda é acentuada no estágio 4 do nível 2 e no estágio 3 do nível 4, que se referem, respectivamente, à preocupação com os outros e capacidade de compreendê-los e à capacidade de compartilhar idéias, combinando e integrando idéias como uma unidade.

Apresentam-se na Tabela 1 os valores de significância obtidos na comparação dos dados de adaptação sócio-comunicativa relatados por diferentes fontes de informação, ou seja pais e terapeutas. É possível notar uma diferença significativa quanto aos estágios 2 e 3 do nível 1, que se referem respectivamente, aos aspectos de referência social - em que a criança deve ser capaz de passar pelas etapas de referência social, utilizando expressões não-verbais do parceiro como referência crítica para suas ações - e à habilidade de ser um aprendiz por meio de um guia - a criança consegue aprender e realizar ações ensinadas pelos pais (guias), seguindo modelos e/ou por meio de imitações. Em ambos os estágios o maior número de respostas positivas foram fornecidas pelos pais.

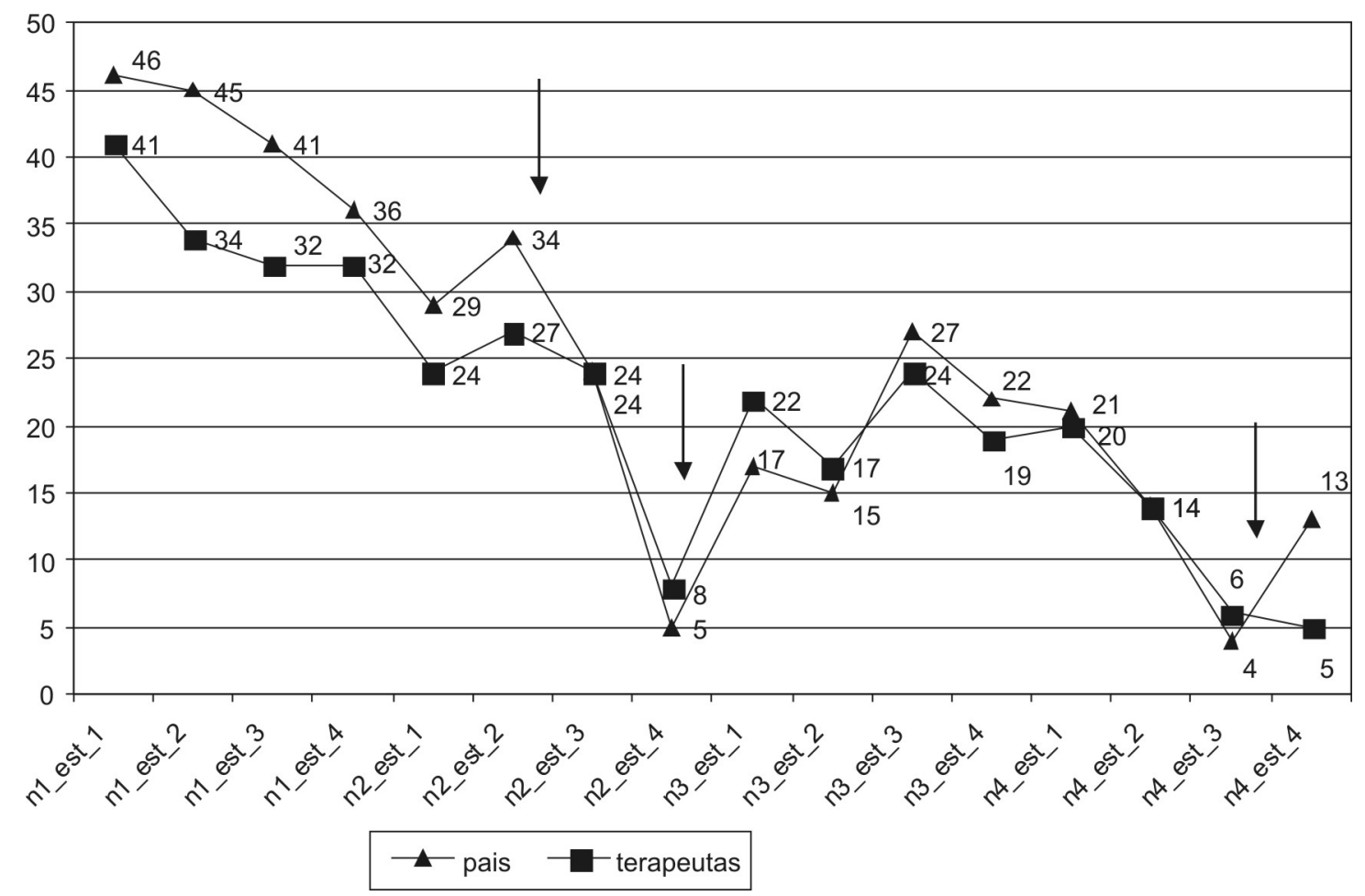

Teste de Wilcoxon, $p<0,050$

Legenda: n1_est_1 = nível 1 estágio 1; n1_est_2 = nível 1 estágio 2; n1_est_3 = nível 1 estágio 3; n1_est_4 = nível 1 estágio 4; n2_est_1 = nível 2 estágio 1; n2_est_2 = nível 2 estágio 2; n2_est_3 = nível 2 estágio 3; n2_est_4 = nível 2 estágio 4; n3_est_1 = nível 3 estágio 1; n3_est_2 = nível 3 estágio 2; n3_est_3 = nível 3 estágio 3; n3_est_4 = nível 3 estágio 4; n4_est_1 = nível 4 estágio 1; n4_est_2 = nível 4 estágio 2; n4_est_3 = nível 4 estágio 3; n4_est_4 = nível 4 estágio $4 ; \rightarrow$ Indicação de diferença estatisticamente significativa

Figura 1. Número de sujeitos com respostas positivas em cada nível/estágio da escala de adaptação sócio-comunicativa, obtidas em entrevistas com os pais e com as terapeutas 
Tabela 1. Valores de significância na comparação dos dados de adaptação sócio-comunicativa obtidos com pais e terapeutas

\begin{tabular}{lc}
\hline Pares de variáveis & Valores de p \\
\hline n1_est_2 (colhido com os pais) X n1_est_2 (colhido com as terapeutas) & 0,001 \\
n1_est_3 (colhido com os pais) X n1_est_3 (colhido com as terapeutas) & 0,029 \\
n4_est_4 (colhido com os pais) X n4_est_4 (colhido com as terapeutas) & 0,033 \\
\hline
\end{tabular}

(Teste de Wilcoxon, $p<0,050)$

Legenda: n1_est_2 = nível 1 estágio 2; n1_est_3 = nível 1 estágio 3; n4_est_4 = nível 4 estágio 4

Tabela 2. Valores de significância (p) obtidos na comparação de respostas dadas por pais e terapeutas, a cada estágio e nível da escala de adaptação sócio-comunicativa

\begin{tabular}{|c|c|c|c|c|c|c|c|c|}
\hline \multirow[t]{3}{*}{$\begin{array}{l}\text { Pares de } \\
\text { comparação }\end{array}$} & $\begin{array}{l}\text { n1_est_1 } \\
\text { (pais) }\end{array}$ & $\begin{array}{l}\text { n1_est_2 } \\
\text { (pais) }\end{array}$ & $\begin{array}{l}\text { n1_est_3 } \\
\text { (pais) }\end{array}$ & $\begin{array}{l}\text { n1_est_4 } \\
\text { (pais) }\end{array}$ & $\begin{array}{l}\text { n2_est_1 } \\
\text { (pais) }\end{array}$ & $\begin{array}{l}\text { n2_est_2 } \\
\text { (pais) }\end{array}$ & $\begin{array}{l}\text { n2_est_3 } \\
\text { (pais) }\end{array}$ & $\begin{array}{l}\text { n2_est_4 } \\
\text { (pais) }\end{array}$ \\
\hline & $x$ & $x$ & $x$ & $x$ & $x$ & $x$ & $x$ & $x$ \\
\hline & $\begin{array}{c}\text { n1_est_1 } \\
\text { (terapeutas) }\end{array}$ & $\begin{array}{c}\text { n1_est_2 } \\
\text { (terapeutas) }\end{array}$ & $\begin{array}{c}\text { n1_est_3 } \\
\text { (terapeutas) }\end{array}$ & $\begin{array}{c}\text { n1_est_4 } \\
\text { (terapeutas) }\end{array}$ & $\begin{array}{c}\text { n2_est_1 } \\
\text { (terapeutas) }\end{array}$ & $\begin{array}{c}\text { n2_est_2 } \\
\text { (terapeutas) }\end{array}$ & $\begin{array}{c}\text { n2_est_3 } \\
\text { (terapeutas) }\end{array}$ & $\begin{array}{c}\text { n4_est_4 } \\
\text { (terapeutas) }\end{array}$ \\
\hline Valores de $p$ & 0,125 & 0,001 & 0,049 & 0,454 & 0,383 & 0,189 & 1,000 & 0,453 \\
\hline \multirow[t]{3}{*}{$\begin{array}{l}\text { Pares de } \\
\text { comparação }\end{array}$} & $\begin{array}{l}\text { n3_est_1 } \\
\text { (pais) }\end{array}$ & $\begin{array}{l}\text { n3_est_2 } \\
\text { (pais) }\end{array}$ & $\begin{array}{l}\text { n3_est_3 } \\
\text { (pais) }\end{array}$ & $\begin{array}{l}\text { n3_est_4 } \\
\text { (pais) }\end{array}$ & $\begin{array}{l}\text { n4_est_1 } \\
\text { (pais) }\end{array}$ & $\begin{array}{l}\text { n4_est_2 } \\
\text { (pais) }\end{array}$ & $\begin{array}{l}\text { n4_est_3 } \\
\text { (pais) }\end{array}$ & $\begin{array}{l}\text { n4_est_4 } \\
\text { (pais) }\end{array}$ \\
\hline & $x$ & $x$ & $x$ & $x$ & $x$ & $x$ & $x$ & $x$ \\
\hline & $\begin{array}{c}\text { n3_est_1 } \\
\text { (terapeutas) }\end{array}$ & $\begin{array}{c}\text { n3_est_2 } \\
\text { (terapeutas) }\end{array}$ & $\begin{array}{c}\text { n3_est_3 } \\
\text { (terapeutas) }\end{array}$ & $\begin{array}{c}\text { n3_est_4 } \\
\text { (terapeutas) }\end{array}$ & $\begin{array}{c}\text { n4_est_1 } \\
\text { (terapeutas) }\end{array}$ & $\begin{array}{c}\text { n4_est_2 } \\
\text { (terapeutas) }\end{array}$ & $\begin{array}{c}\text { n4_est_3 } \\
\text { (terapeutas) }\end{array}$ & $\begin{array}{c}\text { n4_est_4 } \\
\text { (terapeutas) }\end{array}$ \\
\hline Valores de $p$ & 0,383 & 0,774 & 0,648 & 0,607 & 1,000 & 1,000 & 0,688 & 0,057 \\
\hline
\end{tabular}

(Teste de Wilcoxon, $\mathrm{p}<0,050$ )

Legenda: n1_est_1 = nível 1 estágio 1;n1_est_2 = nível 1 estágio 2; n1_est_3 = nível 1 estágio 3; n1_est_4 = nível 1 estágio 4; n2_est_1 = nível 2 estágio 1; n2_est_2 = nível 2 estágio 2; n2_est_3 = nível 2 estágio 3; n2_est_4 = nível 2 estágio 4; n3_est_1 = nível 3 estágio 1; n3_est_2 = nível 3 estágio 2; n3_est_3 = nível 3 estágio 3; n3_est_4 = nível 3 estágio 4; n4_est_1 = nível 4 estágio 1; n4_est_2 = nível 4 estágio 2; n4_est_3 = nível 4 estágio 3; n4_est_4 = nível 4 estágio 4

Observa-se também uma diferença significativa quanto ao estágio 4 do nível 4 em que a criança torna-se capaz de experenciar amigos que dividem os mesmos interesses e experiências em comum, sendo mais uma vez maior o número de respostas positivas dadas pelos pais.

Foi realizada a análise estatística buscando comparar as semelhanças e diferenças entre as respostas dadas por diferentes grupos de pessoas, neste caso, pais e terapeutas, que avaliaram a adaptação sócio-comunicativa de seus filhos (as) e pacientes, respectivamente. Estão apresentadas na Tabela 2 os valores de significância encontrados na aplicação do referido teste.

Os resultados do teste, apresentados na Tabela 2 indicam apenas duas diferenças estatisticamente significantes e uma forte tendência à diferença significante em relação ao estágio 4 do nível 4 , uma vez que o valor de significância encontrado foi de 0,057 . Os dados apresentados na Tabela 2 corroboram os dados apresentados na Figura 1, uma vez que as diferenças estatisticamente significantes encontradas também são referentes aos estágios 2 e 3 do nível 1 e ao estágio 4 do nível 4.

Quanto às diferenças estatisticamente significantes encontradas, observa-se mais especificamente, uma em relação ao estágio 2 do nível 1 , com valor de 0,001 e outra, em relação ao estágio 3 do nível 1 , com valor de 0,049 , estando demonstradas abaixo na Tabela 3 , a comparação de respostas atribuídas pelos diferentes informantes aos referidos níveis e estágios da escala de adaptação sócio-comunicativa.

De acordo com a análise dos resultados estabelecidos pela
Tabela 3. Valores obtidos na comparação das repostas sim ou não dadas por diferentes informantes para os níveis e estágios da escala de adaptação sócio-comunicativa que apresentaram diferença estatisticamente significativa

\begin{tabular}{ccccc}
\hline Níveis /estágios & & $\begin{array}{c}\text { Não- } \\
\text { terapeutas }\end{array}$ & $\begin{array}{c}\text { Sim- } \\
\text { terapeutas }\end{array}$ & Total \\
\hline \multirow{2}{*}{ n1_est_2 } & Não - pais & 3 & 0 & 3 \\
& \% do total & $6,3 \%$ & $0 \%$ & $6,3 \%$ \\
& Sim - pais & 11 & 34 & 45 \\
& $\%$ do total & $22,9 \%$ & $70,8 \%$ & $93,6 \%$ \\
Total & $\%$ do total & 14 & 34 & 48 \\
& & $29,2 \%$ & $70,8 \%$ & $100 \%$ \\
\hline Níveis lestágios & & Não- & Sim- & Total \\
& & terapeutas & terapeutas & \\
\hline \multirow{2}{*}{ n1_est_3 } & Não - pais & 3 & 4 & 7 \\
& $\%$ do total & $6,3 \%$ & $8,3 \%$ & $14,6 \%$ \\
& Sim - pais & 13 & 28 & 41 \\
& $\%$ do total & $27,1 \%$ & $58,3 \%$ & $85,4 \%$ \\
Total & $\%$ do total & 16 & 32 & 48 \\
& & $33,3 \%$ & $66,7 \%$ & $100 \%$ \\
\hline
\end{tabular}

(Teste de McNemar, $\mathrm{p}<0,050$ )

Legenda: n1_est_2 = nível 1 estágio 2; n1_est_3 = nível 1 estágio 3

análise estatística descritiva, pode-se dizer que ocorre uma tendência de semelhança entre as respostas obtidas com pais e terapeutas em relação ao questionário da escala de adaptação sócio-comunicativa. Observa-se que o teste foi bastante homogêneo, demonstrando que as informações podem ser colhidas com diferentes fontes de informantes. 


\section{DISCUSSÃO}

Os dados obtidos neste estudo indicam que houve semelhança no número de respostas sobre a adaptação sócio-comunicativa, obtidas por meio de diferentes fontes de informação, ou seja, pais e terapeutas. Isso deixa claro que a aplicação do questionário e do protocolo de adaptação sócio-comunicativa a diferentes informantes pode fornecer um resultado bastante homogêneo, sendo possível realizar de forma fidedigna a caracterização das habilidades de relacionamento social dessas crianças. Esses dados são compatíveis com as idéias de diversos autores ${ }^{(12-16)}$ no sentido de que a consideração da perspectiva dos pais de crianças do espectro autístico quanto ao comportamento linguístico, cognitivo e social de seus filhos merece destaque, possibilitando que estes se tornem parceiros dos profissionais envolvidos no processo de intervenção, ajudando no monitoramento do nível de desenvolvimento destas crianças.

A análise dos dados revela que os pais apresentaram consistentemente um número maior de respostas positivas do que as terapeutas, para as questões relativas ao desempenho social de seus filhos. Isso pode estar relacionado ao fato de que, um dos fatores importantes na interpretação do comportamento social é o papel da familiaridade, rotinas e estruturação da participação desta criança em atividades sociais ${ }^{(7-8)}$.

Rotinas e atividades estruturadas reduzem a complexidade e a imprevisibilidade do mundo social, o que pode ter sido o fator diferenciador no reconhecimento das habilidades sóciocomunicativas por parte dos pais e das terapeutas, uma vez que a familiaridade com as terapeutas era menor no momento da coleta dos dados. Esses dados corroboram as idéias de que, em contextos familiares, crianças autistas são mais interessadas e responsivas à aproximação das pessoas, apresentando iniciativas comunicativas e ações de cooperação ${ }^{(1,7-8)}$.

Pode-se observar que o comportamento sócio-comunicativo das crianças do espectro autístico é extremamente variável, sendo que este passa a ser cada vez mais diferenciado a partir do momento em que a criança necessita perceber, compreender e aceitar a intervenção do outro como agente de participação, colaboração e de co-criação, o que corrobora a afirmação de que em crianças autistas também ocorre um desenvolvimento significativo das habilidades linguísticas relacionado a melhoras significativas nas habilidades cognitivas e sóciocomunicativas, sendo que este desenvolvimento ocorre em diferentes formas e ritmos, considerando sempre as variações individuais que são aparentes ${ }^{(9)}$.

Este comportamento pode ser notado a partir dos estágios 2 e 3 do nível 2 da escala de adaptação sócio-comunicativa, em que a criança necessita adaptar-se bem a novidades, bem como usar a referência e regulação para funcionar como um parceiro em ações coordenadas, sendo encontradas diversas diferenças estatisticamente significantes em relação a esses estágios e níveis sócio-comunicativos em todo o estudo, e correlações sempre positivas com o número de atos comunicativos totais e expressos por minuto, e percentual de uso do meio verbal, o que pode estar ligado às variações do contexto comunicativo em que estas crianças se desenvolvem, pois este é sensível a dimensões como formalidade da situação, objetivo da interação e relação entre interlocutores ${ }^{(5-6)}$.

\section{CONCLUSÃO}

O estabelecimento de dados de adaptação sócio-comunicativa pode caracterizar esta população, demonstrando que este instrumento pode ser aplicado a diferentes informantes e que as respostas dadas pelos mesmos foram homogêneas, confirmando que os dados foram fidedignos, apesar de existirem diferenças significativas na comparação dos níveis e estágios sócio-comunicativos.

A utilização dos pais e também das terapeutas na coleta dos dados de adaptação sócio-comunicativa mostrou-se de grande valia, possibilitando uma produtiva troca de informações e a formação de parcerias que agem na detecção de possíveis falhas no processo de reabilitação, acompanhando de forma sistemática e objetiva o trabalho terapêutico.

Este trabalho contribui no sentido de fornecer uma forma de analisar e acompanhar o desenvolvimento de habilidades sociais necessárias para as crianças se adaptarem e funcionarem como parceiros, além de incentivar a proposta de programas de intervenção para crianças com distúrbios do desenvolvimento, voltados para as alterações das habilidades sócio-comunicativas, a fim de que estas melhorem suas interações sociais com seus pares, desenvolvendo conjuntamente as habilidades de linguagem, cognição e socialização.

A não caracterização das 48 crianças deste estudo, quanto ao nível intelectual, ao tempo de exposição a outras abordagens terapêuticas e ao grau de escolaridade, bem como a não consideração do grau de escolaridade dos pais das referidas crianças como critérios de inclusão na amostra, podem ser apresentados como possíveis limitações da presente pesquisa, uma vez que estes aspectos podem interferir nos resultados obtidos.

Um outro aspecto relevante neste trabalho é a necessidade de estudos sobre a adaptação sócio-comunicativa de crianças em desenvolvimento típico, utilizando pais, familiares e cuidadores como informantes. Crianças em desenvolvimento típico apresentam formas de comunicação e socialização progressivamente mais elaboradas. Nesse processo, áreas específicas e independentes como a cognição, a linguagem e a socialização desenvolvem-se, gerando diferentes interações entre seus elementos. A investigação deste processo e de suas relações com as diferentes áreas do desenvolvimento é fundamental para que dados de normalidade sejam estabelecidos e possam ajudar como possíveis parâmetros de comparação da evolução clínica e diagnóstica de crianças com distúrbios do desenvolvimento.

\section{AGRADECIMENTOS}

À Coordenação de Aperfeiçoamento de Pessoal de Nível Superior (CAPES), pelo apoio concedido para realização desta pesquisa. 


\begin{abstract}
Purpose: To verify if the application of the social-communicative adaptation protocol with different information sources, in this case, parents and therapists, is effective to identify individual differences in children of the autistic spectrum. Methods: Subjects were 48 children, with ages ranging from three to 11 years and ten months, with psychiatric diagnosis included in the autistic spectrum. The parents of those children (46 mothers and two fathers) and 15 speech therapists, who were, respectively, legal caregivers and responsible for their speech-language therapy for at least 12 months, were also subjects of the study. They answered a questionnaire regarding each child's social relation performance. Results: Generically, it is possible to say that the answers obtained from different sources (parents and therapists) were similar. However, the analysis of raw data showed that parents consistently presented higher number of positive answers when compared to therapists, in questions regarding social performance. Conclusion: The determination of data about social-communicative adaptation could characterize these subjects, demonstrating that this protocol can be used with different information sources; the answers provided by parents and therapists were homogeneous, confirming data reliability despite of significant differences in the comparison among social-communicative stages and levels. The application of the questionnaire and the social communicative protocol to different information sources can provided homogeneous results, allowing a reliable characterization of these children's social abilities.
\end{abstract}

Keywords: Autistic disorder; Socialization; Communication; Language therapy; Parents

\title{
REFERÊNCIAS
}

1. Tager-Flusbeg H. Brief report: current theory and research on language and communication in autism. J Autism Dev Disord. 1996;26(2):16972.

2. Tager-Flusberg H. Language and understanding minds: connection in autism. In: Baroh-Cohen S, Tager-Flusbger H, Cohen DJ. Understanding others minds: perspectives from developmental cognitive neuroscience. 2a ed. New York: Oxford University Press; 2000. p.124-49.

3. Fernandes FDM. Atuação fonoaudiológica com crianças com transtornos do espectro autístico [tese]. São Paulo: Faculdade de Medicina da Universidade de São Paulo; 2002.

4. Hale CM, Tager-Flusberg H. Social communication in children with autism: the relationship between theory of mind and discourse development. Autism. 2005;9(2):157-78.

5. Yont KM, Snow CE, Vernon-Feagans L. The role of context in motherchild interactions: an analysis of communicative intents expressed during toy play and book reading with 12-month-olds. J Pragmatics. 2003;35(3):435-54.

6. Theakston AL, Lieven EV. The influence of discourse context on children's provision of auxiliary BE. J Child Lang. 2008;35(1):129-58.

7. Tager-Flusberg H. A psychological approach to understanding the social and language impairments in autism. Int Rev Psychiatry. 1999;11(4):325-34.

8. Müller E, Schuler A, Yates GB. Social challenges and supports from the perspective of individuals with Asperger syndrome and other autism spectrum disabilities. Autism. 2008;12(2):173-90.

9. Turner LM, Stone WL, Pozdol SL, Coonrod EE. Follow-up of children with autism spectrum disorders from age 2 to age 9 . Autism. 2006;10(3):243-65.

10. Morato PFS. Perfil funcional da comunicação e adaptação sóciocomunicativa no espectro autístico [tese]. São Paulo: Faculdade de Filosofia, Letras e Ciências Humanas da Universidade de São Paulo; 2007.

11. Sousa PFG. Relações entre o perfil comunicativo, desempenho sócio- cognitivo e adaptação sócio-comunicativa em crianças com transtornos do espectro autístico [dissertação]. São Paulo: Faculdade de Filosofia, Letras e Ciências Humanas da Universidade de São Paulo; 2004.

12. Luiselli JK, Campbell S, Cannon B, DiPietro E, Ellis JT, Taras M, Lifter K. Assessment instruments used in the education and treatment of persons with autism: brief report of a survey of national service centers. Res Dev Disabil. 2001;22(5):389-98.

13. Charman T, Howlin P, Berry B, Prince E. Measuring developmental progress of children with autism spectrum disorder on school entry using parent report. Autism. 2004;8(1):89-100.

14. Siperstein R, Volkmar F. Brief report: parental reporting of regression in children with pervasive developmental disorders. J Autism Dev Disord. 2004;34(6):731-4.

15. Eaves LC, Wingert HD, Ho HH, Mickelson EC. Screening for autism spectrum disorders with the social communication questionnaire. J Dev Behav Pediatr. 2006;27(2 Suppl):S95-S103.

16. Moes DR, Frea WD. Contextualized behavioral support in early intervention for children with autism and their families. J Autism Dev Disord. 2002;32(6):519-33.

17. Posserud B, Lundervold AJ, Steijnen, MC, Verhoeven S, Stormark KM, Gillberg C. Factor analysis of the Autism Spectrum Screening Questionnaire. Autism. 2008;12(1):99-112.

18. Tyler AA, Tolbert LC. Speech-language assessment in the clinical setting. Am J Speech Lang Pathol. 2002;11(3):215-20.

19. American Psychiatry Association. DSM-IV. Manual diagnóstico e estatístico de transtornos mentais. Traduzido por Dayse Batista. 4a ed. Porto Alegre: Artes Médicas; 1994.

20. Organização Mundial de Saúde. Classificação de transtornos mentais de comportamento da CID-10: critérios diagnósticos para pesquisa. Traduzido por Maria Lúcia Domingues.10a ed. Porto Alegre- RS, Artes Médicas; 1983.

21. Rosner B. Fundamentals of biostatistics. 2nd ed. Belmont: Duxburry; 1986. 
Anexo 1. Questionário - Escala de Adaptação Sócio-Comunicativa (EASC) ${ }^{(11)}$

\section{Nível 1: Principiante}

\section{Estágio 1: Sintonia}

Objetivo: saber se a criança realiza contato visual significativo com os pais, terapeutas ou cuidadores e/ou ri de expressões faciais apresentadas pelos mesmos.

Exemplos:

1-Quando algum familiar se esconde e aparece repentinamente como em brincadeiras de "achou", a criança ri?

2-Dá risadas quando alguma novidade é introduzida, alguma brincadeira diferente é realizada?

\section{Estágio 2: Referência Social}

Objetivo: passar pelas etapas de referência social, utilizando expressões não-verbais do parceiro como referência crítica para suas ações. Saber se a criançaconsegue perceber as expressões faciais e preocupa-se com a compreensão e reação.

Exemplos:

1-Se os pais, terapeutas fazem cara de bravos, ou de ansiosos e preocupados com alguma ação da criança que possa ser perigosa, como cair de uma escada, esta consegue perceber e adequar seu comportamento?

2-A criança apresenta curiosidade pelos outros oferecendo objetos, brinquedos aos mesmos para observar suas reações?

\section{Estágio 3: Aprendiz/ Guia}

Objetivo: saber se a criança consegue aprender e realizar ações ensinadas pelos pais (guias), seguindo modelos e/ou por meio de imitações.

Exemplos:

1-Quando os pais ou terapeutas propõem-se em ensinam alguma ação, como montar um brinquedo, a criança consegue aprender imitando-os?

2-Enquanto os pais ou terapeutas guiam as crianças para aprender alguma ação, estas se mostram interessadas pela novidade e mantêm essa experiência de troca em foco, ou mudam o foco de sua atenção?

\section{Estágio 4: Coordenação Social}

Objetivo: saber se a criança é capaz de coordenar com o parceiro, ações simples, das quais os dois possam desfrutar mutuamente, portanto, saber se a criança consegue realizar trocas de turno.

Exemplos:

1-Se jogar um brinquedo, como uma bola, a criança é capaz de jogar novamente?

2-Em uma montagem de uma torre com blocos de encaixe a criança consegue alternar com o parceiro a colocação das peças, para depois os dois juntos derrubarem-nas?

\section{Nível 2: Aprendiz}

\section{Estágio 1: Variação}

Objetivo: saber se a criança é capaz de gostar e reagir bem ou não às novidades introduzidas

Exemplos:

1-Na brincadeira de basquete, a criança aceita variar o uso da cesta de basquete, pela cesta de lixo, aceitando bem a pequena mudança e até propondo novas possibilidades?

2-Na brincadeira de boliche, no lugar da bola, ela aceita que se jogue outro objeto?

\section{Estágio 2: Adaptação}

Objetivo: saber se a criança é capaz de adaptar-se bem a introdução de alguma novidade, ou melhor, depois que se insere uma novidade, a criança também é capaz de brincar com a mesma.

Exemplos:

1-Se os pais, terapeutas chegam com um novo brinquedo, a criança pega e brinca com o mesmo ou somente explora-o e volta a brincar com o brinquedo antigo?

2-Se a criança come sempre com um mesmo prato, ou bebe sempre no mesmo copo a criança é capaz de aceitar a novidade ou não se adapta a esta?

\section{Estágio 3: Sincronização}

Objetivo: saber se a criança consegueusar o outro como referência e regulação para coordenar suas ações.

Exemplos:

1-A criança consegue seguir um referencial social como na brincadeira de siga o líder co-regulando seu comportamento?

2-A criança realiza brincadeiras de esconde-esconde, e quando é encontrada demonstra grande alegria como resposta à reação do parceiro?

\section{Estágio 4: Preocupação com os outros}

Objetivo: saber se a criança é capaz de perceber e identificar comportamentos e emoções, modificando seu comportamento para um maior aproveitamento das experiências compartilhadas.

Exemplos:1-A criança ao brincar seu jogo favorito com um parceiro é capaz de perceber que este está distraído e entediado, e perguntar ao mesmo se está aborrecido e sugerir um novo jogo?

2-Em uma situação de brincadeira com uma bola, a criança é capaz de perceber que seu parceiro não está conseguindo pegar a bola, porque ela está jogando a bola muito forte, modificando assim o seu comportamento?

\section{Nível 3: Desafiante}

\section{Estágio 1: Colaboração}

Objetivo: se a criança consegue balancear ações de co-regulação (regular seu comportamento em base de um referencial social) e ações de co-variação (estabelecer relações de variações mutuamente com o parceiro em uma determinada atividade) em atividades de cooperação entre os parceiros.

Exemplos:

1-Quando em uma brincadeira o parceiro fala que o seu carrinho ficará em um determinado lugar, e a criança diz que não, que ali ficará o carrinho dela. A criança consegue negociar com o outro qual carrinho ficará no lugar determinado?

2-Quando a criança quer realizar uma determinada brincadeira e o parceiro diz que agora eles vão fazer uma brincadeira diferente, a criança aceita e brinca normalmente negociando quando poderão realizar a outra brincadeira?

\section{Estágio 2: Co-criação}

Objetivo: se a criança é capaz de descobrir sua criatividade e imaginação, aprendendo a se divertir como um parceiro igual na co-criação. Exemplos:

1-A criança e o parceiro estão montando um carro com peças de Lego, eles conseguem pensar juntos em outra forma de brincar com as peças?

2-Nesta mesma situação, a criança dá e aceita sugestões de como poderia ser montado o brinquedo?

\section{Estágio 3: Improvisação}

Objetivo: saber se a criança consegue lidar em situações imprevistas, conseguindo manter o contato social.

Exemplos:

1-Em uma situação em que chegam pessoas estranhas na casa, ou na sala de terapia sem avisar, a criança consegue chegar perto e realizar contato com as mesmas?

2-Quando acontece alguma situação ou fato que não era esperado a criança apresenta-se agitada, confusa ou consegue utilizar a linguagem para regular a situação? 


\section{Estágio 4: Percepções compartilhadas}

Objetivo: saber se a criança é capaz de experenciar a alegria de dividir percepções com amigos, ou seja, se ela realiza comentários a respeito de ações e fatos ocorridos. Pode ocorrer em todos os meios comunicativos.

Exemplos:

1-Quando passa algum avião, ambulância ou faz algum barulho forte a criança realiza comentários, chama para ver o que está acontecendo a fim de buscar sua atenção conjunta para o fato?

2-A criança realiza comentários de fatos que ocorreram na escola ou em outros lugares, buscando sua atenção?

\section{Nível 4: Desbravador}

\section{Estágio 1: Perspectivas compartilhadas}

Objetivo: se a criança é capaz de aprender a valorizar o ponto de vista do outro.

Exemplos:

1-A criança é capaz de aceitar a opinião dos outros como uma possibilidade?

2-A criança demonstra curiosidade pela opinião dos outros e aceita-a com o mesmo valor como as suas próprias perspectivas?

\section{Estágio 2: Imaginação compartilhada}

Objetivo: se a criança é capaz de aproveitar e combinar as imaginações compartilhadas entre si e o parceiro.

\section{Exemplos:}

1-A criança dá opiniões e gosta de compartilhar suas idéias? 2-A criança é capaz de aproveitar uma idéia dada pelos pais ou terapeutas e combinar com suas próprias idéias, como em uma brincadeira com uma boneca, o parceiro coloca um biquíni na boneca e a criança propõe que a boneca vai para a praia?

\section{Estágio 3: Compartilhando idéias}

Objetivo: se a criança consegue combinar e integrar idéias como uma unidade.

Exemplos:

1-A criança é capaz de juntar uma idéia que teve com a idéia de um amigo, e formar uma só idéia?

2-A criança fala que eles poderiam criar um animal diferente, o parceiro pensa em um elefante e a criança em uma zebra, os dois juntos são capazes de combinar estes dois animais e criar um só, ou seja, uma "elezebra"?

\section{Estágio 4: Amigos}

Objetivo: se a criança é capaz de experenciar amigos que dividem os mesmos interesses e experiências em comum.

Exemplos:

1-A criança tem relações de amizade verdadeiras, sente saudades, pede para ver?

2-A criança é sempre capaz de estabelecer relações de jogos com estes parceiros?

Anexo 2. Protocolo de registro - Escala de Adaptação Sócio-Comunicativa (EASC) ${ }^{(11)}$

Identificação:

Nome: Idade:

Nome do responsável:

Nível 1: Principiante

\begin{tabular}{|c|c|c|c|c|}
\hline Estágios & Classificação & Ações realizadas & Sim & Não \\
\hline Estágio 1 & Sintonia & $\begin{array}{l}\text { Compartilhando as experiências e emoções, com } \\
\text { ações face a face. }\end{array}$ & & \\
\hline Estágio 2 & Referência social & $\begin{array}{l}\text { Usando expressões não- verbais do parceiro } \\
\text { como ponto de referência crítica para suas } \\
\text { ações. }\end{array}$ & & \\
\hline Estágio 3 & Aprendiz/Guia & $\begin{array}{l}\text { Tornando-se um bom aprendiz através de um } \\
\text { adulto como guia. }\end{array}$ & & \\
\hline Estágio 4 & Coordenação social & $\begin{array}{l}\text { Sincronizando ações simples para aproveita- } \\
\text { mento mútuo. }\end{array}$ & & \\
\hline
\end{tabular}

Nível 2: Aprendiz

\begin{tabular}{|c|c|c|c|c|}
\hline Estágios & Classificação & Ações realizadas & Sim & Não \\
\hline Estágio 1 & Variação & $\begin{array}{l}\text { Aprendendo a gostar de variações e novidades } \\
\text { quando cuidadosamente introduzidas. }\end{array}$ & & \\
\hline Estágio 2 & Adaptação & $\begin{array}{l}\text { Conseguindo a se adaptar a mudanças e va- } \\
\text { riações. }\end{array}$ & & \\
\hline Estágio 3 & Sincronização & $\begin{array}{l}\text { Usando referência e regulação para funcionar } \\
\text { como um parceiro em ações coordenadas. }\end{array}$ & & \\
\hline Estágio 4 & $\begin{array}{l}\text { Preocupação com os } \\
\text { outros }\end{array}$ & $\begin{array}{l}\text { Aprendendo a identificar, fazer referências na } \\
\text { mudança do aproveitamento e compreensão do } \\
\text { parceiro tornando-os guias críticos para suas } \\
\text { ações. }\end{array}$ & & \\
\hline
\end{tabular}


Nível 3: Desafiante

\begin{tabular}{|l|l|l|l|l|}
\hline Estágios & Classificação & Ações realizadas & Sim & Não \\
\hline Estágio 1 & Colaboração & $\begin{array}{l}\text { Equilibrando co-regulação com co-variação } \\
\text { em atividades de cooperação com parceiro da } \\
\text { mesma idade. }\end{array}$ & $\begin{array}{l}\text { Descobrindo sua criatividade e imaginação. } \\
\text { Aprendendo a desfrutar como um igual ao par- } \\
\text { ceiro na co-criação. }\end{array}$ & \\
\hline Estágio 2 & Co- criação & Praticando encontros improvisados & & \\
\hline Estágio 3 & Improvisação & $\begin{array}{l}\text { Percepções comparti- } \\
\text { Ihadas }\end{array}$ & $\begin{array}{l}\text { Experienciando entusiasmo em dividir percep- } \\
\text { ções com amigos }\end{array}$ & \\
\hline Estágio 4 &
\end{tabular}

Nível 4 : Desbravador

\begin{tabular}{|c|c|c|c|c|}
\hline Estágios & Classificação & Ações realizadas & Sim & Não \\
\hline Estágio 1 & Perspectivas & Aprendendo o valor do ponto de vista do outro. & & \\
\hline Estágio 2 & $\begin{array}{l}\text { Imaginação comparti- } \\
\text { lhada }\end{array}$ & $\begin{array}{l}\text { Demonstra a alegria de compartilhar imagina- } \\
\text { ções. }\end{array}$ & & \\
\hline Estágio 3 & Compartilhando idéias & $\begin{array}{l}\text { Combinando e integrando idéias como uma } \\
\text { unidade. }\end{array}$ & & \\
\hline Estágio 4 & Amigos & $\begin{array}{l}\text { Experienciando amigos que dividem experiências } \\
\text { em comum. }\end{array}$ & & \\
\hline
\end{tabular}

\begin{tabular}{|l|l|l|l|l|}
\hline Estágios/Níveis & Nível 1: Principiante & Nível 2: Aprendiz & Nível 3: Desafiante & Nível 4: Desbravador \\
\hline Estágio 1 & Sintonia & Variação & Colaboração & Perspectivas \\
\hline Estágio 2 & Referência social & Adaptação & Co-criação & $\begin{array}{l}\text { Imaginação compartilha- } \\
\text { da }\end{array}$ \\
\hline Estágio 3 & Aprendiz/Guia & Sincronização & Improvisação & Compartilhando idéias \\
\hline Estágio 4 & Coordenação social & $\begin{array}{l}\text { Preocupação com os ou- } \\
\text { tros }\end{array}$ & $\begin{array}{l}\text { Percepções compartilha- } \\
\text { das }\end{array}$ & Amigos \\
\hline
\end{tabular}

